\title{
Use of octreotide in the acute management of bleeding esophageal varices
}

\author{
Daniel C Sadowski MD FRCPC
}

\begin{abstract}
DC Sadowski. Use of octreotide in the acute management of bleeding esophageal varices. Can J Gastroenterol 1997;11(4): 339-343. Acute hemorrhage from esophageal varices is a medical emergency; despite early diagnosis and treatment the associated hospital mortality remains high. The clinical research summarized in this paper shows that octreotide has a beneficial effect on portal hemodynamics in cirrhotic patients. In randomized controlled trials octreotide has been effective in halting initial hemorrhage and in preventing reoccurrence of bleeding. Somatostatin and octreotide appear to be equivalent in terms of therapeutic efficacy but octreotide is the less expensive option. For suspected variceal bleeding an octreotide infusion should be initiated immediately. To prevent further bleeding the drug should be continued for two to five days after endoscopic variceal ligation.
\end{abstract}

Key Words: Bleeding esophageal varices, Octreotide

The call came at 3:00 am. I clumsily reached for the phone in the dark, trying to clear my fuzzy head. I groaned; night calls to a gastroenterologist usually mean one of two things: an upper gastrointestinal bleed or a foreign body in the esophagus, both of which often require urgent endoscopy.

"Good morning doctor," said the unreasonably cheerful casualty officer. "We have a 45-year-old male who began vomiting blood $2 \mathrm{~h}$ ago." I sighed and began fumbling for my slippers.

"He was hypotensive on arrival to the emergency department but responded quickly to $2 \mathrm{~L}$ of normal saline." I reached for my car keys.

"He has known liver cirrhosis and previous bleeding from esophageal varices one year ago. He was subsequently lost to follow-up." I put down the keys.

"On examination he is alert with a stable blood pressure and

\section{Emploi d'un octréotide dans le traitement d'une rupture de varices œsophagiennes}

RÉSUMÉ : L'hémorragie aiguë associée aux varices œesophagiennes est une situation d'urgence médicale. Malgré un diagnostic et un traitement précoces, la mortalité qui y est associée reste élevée durant l'hospitalisation. La recherche clinique sur les octréotides résumée dans cet article démontre que ces derniers exercent un effet bienfaisant sur l'hémodynamie portale chez les patients cirrhotiques. Dans le cadre d'essais randomisés contrôlés, les octréotides se sont révélés efficaces à freiner l'hémorragie initiale et à prévenir la reprise du saignement. La somatostatine et les octréotides semblent être équivalents sur le plan thérapeutique, mais les octréotides sont une option moins coûteuse. Lorsqu'on soupçonne une rupture de varices œsophagiennes, il faut immédiatement amorcer une perfusion d'octréotides. Pour empêcher la poursuite du saignement, le médicament doit être maintenu de deux à cinq jours après la ligature endoscopique des varices. no postural changes. He has spider nevi on his anterior chest, a palpable spleen and moderate ascites." I took off my slippers.

"His hemoglobin is 110 and his PT INR is 1.3. What do you want me to do?"

"Right," I said confidently, lying back down in my soft bed. "Let us start some octreotide. Give him a $50 \mu \mathrm{g}$ bolus IV now and then begin an infusion of $50 \mu \mathrm{g} / \mathrm{h}$. Admit him and plan for urgent endoscopy first thing this morning." I promptly fell asleep, confident that my patient was receiving the best treatment for his bleeding esophageal varices.

cute hemorrhage from esophageal varices is a medical pital mortality rates approach $25 \%$ (1). The major cause of death is cardiovascular collapse resulting from either the initial hemorrhage or a rebleeding event. Patients who survive the initial bleeding episode often succumb to hepatic decom-

Division of Gastroenterology, Department of Medicine, University of Alberta, Edmonton, Alberta

Correspondence: Dr DC Sadowski, 2E1.14 Walter Mackenzie Health Science Centre, University of Alberta, Edmonton, Alberta T6G 2 R7.

Telephone 403-492-0126, fax 403-492-3340, e-mail dan.sadowski@ualberta.ca

Received for publication August 12, 1996. Accepted January 7, 1997 
pensation or sepsis. Available therapeutic modalities for acute variceal bleeding include vasoactive drugs, balloon tamponade, endoscopic variceal ligation, sclerotherapy and portocaval shunting procedures. Recently, attention has focused on octreotide as a treatment modality for those bleeding from esophageal varices. The purpose of this review is to present the relevant clinical research on octreotide and suggest a rational approach to the use of this drug.

\section{OCTREOTIDE, SOMATOSTATIN AND PORTAL HEMODYNAMICS}

Octreotide is a synthetic analogue of naturally occurring somatostatin-14. In pharmacological doses this octapeptide inhibits gastrointestinal exocrine secretions and stimulates intraluminal fluid absorption $(2,3)$. While the biological effects of this peptide are essentially those of native somatostatin, octreotide appears to be more potent and to have a dramatically longer half-life $(4,5)$. Unlike somatostatin, octreotide can be administered subcutaneously.

Because of the inaccessibility of the portal vein in humans, indirect methods such as hepatic vein catheterization or Doppler flowmetry have been employed in the study of portal hemodynamics. In cirrhotic patients, several investigators (6-10) have observed a significant decrease in estimated portal venous pressure after administration of somatostatin and octreotide. This effect persisted for up to $3 \mathrm{~h}$ after the octreotide infusion was stopped (11). The responsible mechanisms are unknown but may involve direct vasoconstriction of splanchnic vasculature, vasodilation of the portal system or inhibition of vasoactive hormones such as glucagon (12). However, not all investigators have confirmed these pressure-related findings $(13,14)$. For example, Lin et al (15), in a study of 20 patients with hepatitis B cirrhosis, did not find any change in the hepatic venous pressure gradient after either low or high dose infusions of octreotide.

More consistent measurements have been observed using measurements of azygous vein flow, which reflects collateral and variceal bloodflow. Reproducible reductions in azygous bloodflow have resulted from both octreotide and somatostatin infusions $(10,16)$. Intravariceal pressure can be measured using either fine needle puncture or compression techniques. A close correlation appears to exist between variceal bleeding events and elevated intravariceal pressure (17). The effects of somatostatin or octreotide infusions on intravariceal pressure are under debate. Investigators have reported both increases and decreases in pressure during drug infusions (18-20). The heterogeneity of these responses may be due to differences in measurement techniques, disease severity and/or systemic vascular effects of the drugs.

\section{CLINICAL TRIALS WITH SOMATOSTATIN AND OCTREOTIDE}

Clinical trials involving patients with acute bleeding from esophageal varices have evaluated the effects of somatostatin compared with those of placebo, vasopressin and injection sclerotherapy. In a randomized double-blind trial, Burroughs and co-workers (21) demonstrated that intrave-

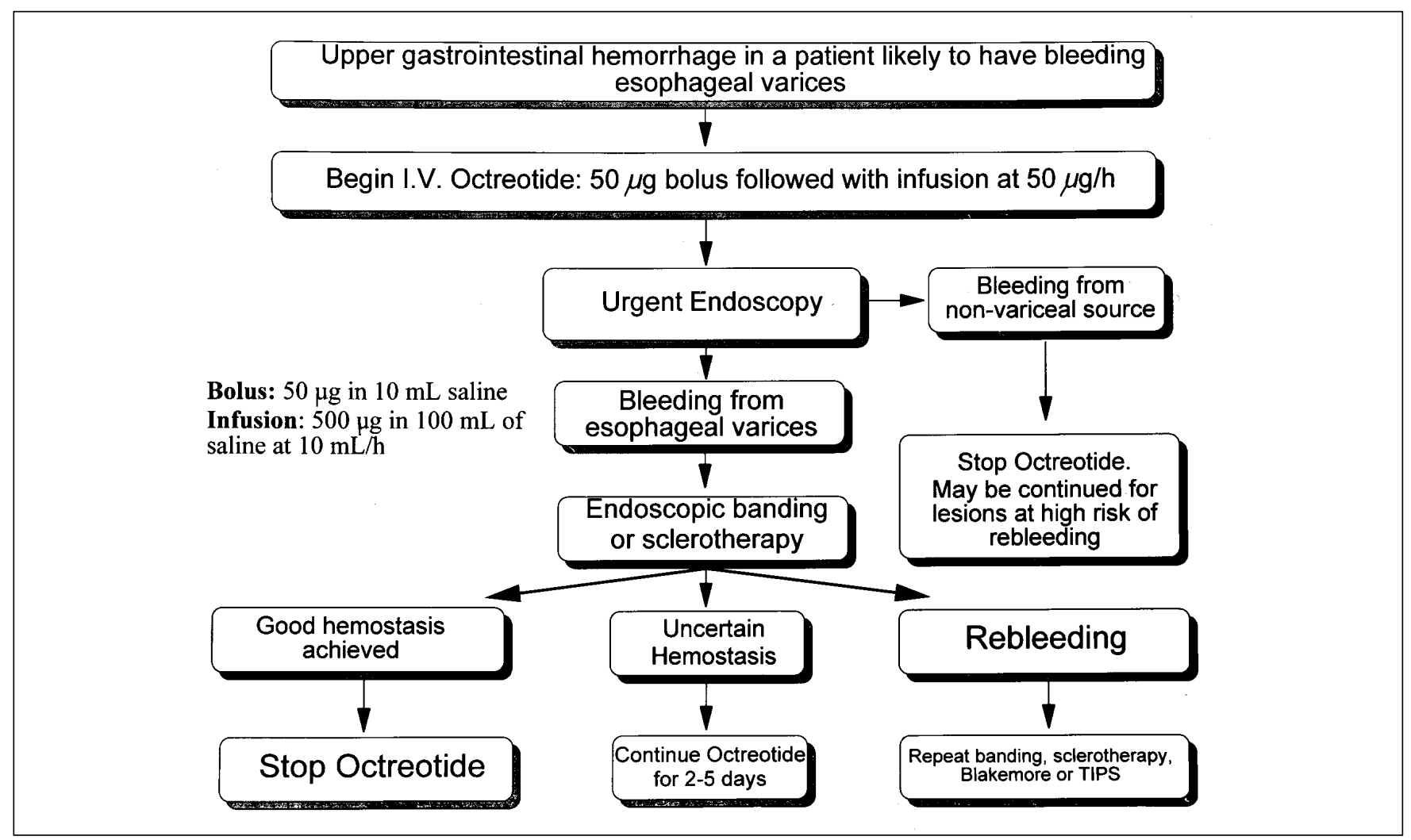

Figure 1) An approach to the use of octreotide for the treatment of acute hemorrhage from esophageal varices. IV Intravenous; TIPS Transjugular intrahepatic portosystemic shunt 
nous somatostatin $(250 \mu \mathrm{g} / \mathrm{h})$ over five days was superior to placebo in controlling initial hemorrhaging, as well as in reducing early rebleeding and transfusion requirements. Valenzuela et al (22) were unable to reproduce a therapeutic effect in a similarly designed trial; however, the high response rate $(83 \%)$ in the placebo group suggests significant patient selection bias. A recent meta-analysis of published clinical trials examined the relative therapeutic efficacies of somatostatin and vasopressin. Somatostatin was more efficacious than vasopressin in controlling acute variceal hemorrhage; somatostatin also had a lower rate of adverse events (23). Somatostatin compared favourably with balloon tamponade in the control of initial hemorrhage $(24,25)$. In a study of 70 patients, Planas et al (26) demonstrated that somatostatin by infusion was as effective as injection sclerotherapy in both controlling initial bleeding episodes and preventing early rebleeding. Also, significantly fewer major complications were observed in the somatostatin group (26).

An overview of published clinical trials on octreotide is found in Table 1. In one study of 100 patients, Sung et al (27) demonstrated that octreotide was as effective as emergency sclerotherapy in controlling initial hemorrhage and preventing rebleeding episodes. In that trial the majority of rebleeding episodes occurred within $48 \mathrm{~h}$ of presentation. In a subsequent study, the same investigators demonstrated that octreotide in combination with endoscopic band ligation significantly reduced the incidence of early rebleeding over band ligation alone (28). Besson's group (29) found a significant reduction in early rebleeding in 199 patients when octreotide was combined with standard sclerotherapy (29). McKee et al (30) found octreotide to be as effective as balloon tamponade in controlling initial hemorrhage. In an attempt to reduce rebleeding, Primignani et al (31) used subcutaneous injections of octreotide ( $300 \mu \mathrm{g} /$ day) for up to 29 days after the initial bleeding episode had been controlled with endoscopic sclerotherapy. No difference in rebleeding rates was found between treatment or placebo groups; however, this lack of difference may be a function of the low dose used (31). Octreotide has also been found to be more effective than vasopressin and its longer acting analogue terlipressin in controlling acute bleeding; as well, substantially fewer side effects were noted in the octreotide group (32-34). In all of the studies cited above, no difference was seen in patient mortality between treatment groups. The exception was the study from McKee and colleagues (30), which found a substantially higher mortality in the esophageal tamponade group.

\section{AN APPROACH TO THE MANAGEMENT OF BLEEDING ESOPHAGEAL VARICES}

The goals of treatment in acute variceal bleeding are to control the initial hemorrhage, prevent early rebleeding, minimize deterioration in liver function and treat complications associated with blood loss (35). Priority is given to airway management, along with early establishment of good venous access. Resuscitation involves administration of intravenous

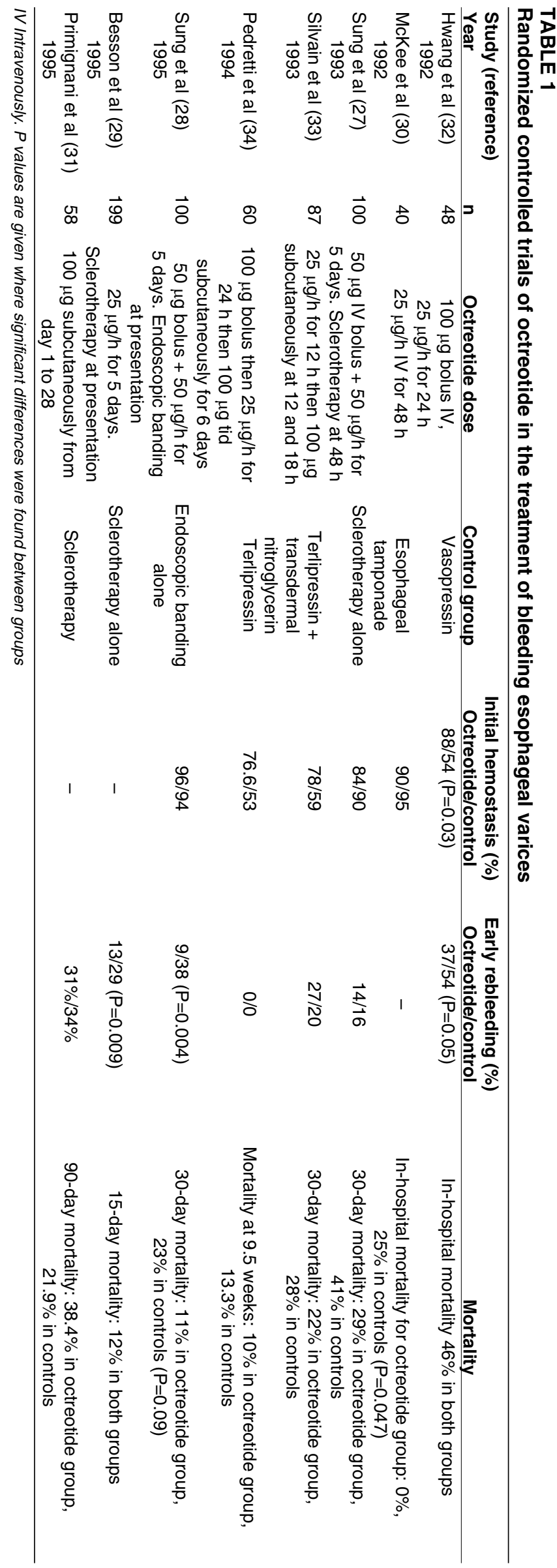


crystalloid solutions and transfusion of packed red blood cells and clotting factors where appropriate.

Many centres favour endoscopic sclerotherapy or band ligation once the patient has been stabilized. The advantage to this approach is that the site of bleeding can be identified and the hemorrhage controlled in most instances. While endoscopic banding appears to be safer than injection sclerotherapy, banding is not always possible if the patient is bleeding briskly or visibility is poor $(36,37)$. The main difficulty in banding or sclerotherapy is that endoscopy facilities are not available in many centres on an emergency basis. In addition, even in experienced hands rebleeding rates after sclerotherapy or banding are as high as $40 \%(36,37)$. Therefore, a therapeutic agent that can be easily administered while the patient is being stabilized and transferred to an endoscopy facility is necessary. Vasopressin has traditionally been used in this capacity. However, because of vasopressin's side effect profile and the need for concomitant nitroglycerin administration, investigators have continued to search for better vasoactive agents. Unfortunately, while synthetic analogues of vasopressin such as terlipressin have proven efficacious, they have also similar adverse effects $(33,38)$.

As discussed earlier, somatostatin and octreotide have proven efficacy in controlling the initial hemorrhage and in preventing rebleeding events. Moreover, in clinical trials the side effect profiles of both somatostatin and octreotide are minimal. While no head-to-head trials have been performed on these two agents, available evidence suggests a similar therapeutic response. While the acquisition cost per microgram of both products is similar, the required dosage of somatostatin is five times that of octreotide $(250 \mu \mathrm{g} / \mathrm{h}$

\section{REFERENCES}

1. Graham DY, Smith JL. The course of patients after variceal hemorrhage. N Engl J Med 1981;80:800-9.

2. Gullo L, Billotti G, Pezzilli R, Di Stefano M, Ancona D. Effect of octreotide (SMS 201-995) on meal-stimulated pancreatic secretion in three patients with external pancreatic fistula. Am J Gastroenterol 1991;86:892-4.

3. Creutzfeldt W, Lembcke B, Folsch UR, Schleser S, Koop I. Effect of somatostatin analogue (SMS 201-995, Sandostatin) on pancreatic secretion in humans. Am J Med 1987;82:49-54.

4. Bauer W, Briner U, Doepfner W, et al. SMS 201-995: a very potent and selective octapeptide analogue of somatostatin with prolonged action. Life Sci 1982;31:1133-40.

5. Del Pozo E, Neufeld M, Schluter K, et al. Endocrine profile of a long-acting somatostatin derivative SMS 201-995. Study in normal volunteers following subcutaneous administration. Acta Endocrinol (Copenh) 1986;111:433-9.

6. Eriksson LS, Brundin T, Soderlund C, Wahren J. Haemodynamic effects of a long-acting somatostatin analogue in patients with liver cirrhosis. Scand J Gastroenterol 1987;22:919-25.

7. Pringle SD, McKee RF, Garden OJ, Lorimer AR, Carter DC. The effect of a long-acting somatostatin analogue on portal and systemic haemodynamics in cirrhosis. Aliment Pharmacol Ther 1988;2:451-9.

8. Albillos A, Rossi I, Iborra J, et al. Octreotide prevents postprandial splanchnic hyperemia in patients with portal hypertension. J Hepatol 1994;21:88-94.

9. McCormick PA, Biagini MR, Dick R, et al. Octreotide inhibits the meal-induced increases in the portal venous pressure of cirrhotic patients with portal hypertension: a double-blind, placebo-controlled study. Hepatology 1992;16:1180-6.

10. Mastai R, Bosch J, Navasa M, et al. Effect of continous infusion and bolus injections of somatostatin (SMT) on azygous blood flow and versus $50 \mu \mathrm{g} / \mathrm{h})$. The cost in Canadian dollars for $48 \mathrm{~h}$ of treatment is $\$ 840.50$ for somatostatin versus $\$ 252.52$ for octreotide.

Figure 1 presents an approach to therapy incorporating octreotide for the patient with suspected bleeding esophageal varices. It seems reasonable to begin octreotide at presentation for any patient with upper gastrointestinal hemorrhage who has a high clinical likelihood of bleeding esophageal varices. The drug can be given while the patient is being stabilized or during transfer to an endoscopy centre. If a nonvariceal bleeding lesion is found during endoscopy, the drug can be discontinued, although some investigators feel that there is evidence for efficacy with high risk bleeding peptic ulcers (39). Following treatment with sclerotherapy or banding, octreotide should be continued for two to five days to prevent rebleeding episodes. For patients who experience further rebleeding, available treatment options include balloon tamponade, repeat endoscopic banding or portocaval shunting. It should be emphasized that octreotide should not be used as a substitute for timely and urgent endoscopy in the bleeding patient. Patients who fail to stabilize with appropriate resuscitation require urgent endoscopy, whether or not octreotide has been used.

\section{CONCLUSIONS}

Octreotide is a new peptide analogue effective in the treatment of bleeding esophageal varices. In clinical trials it has proven equivalence to esophageal banding in controlling initial hemorrhaging, and it is superior to banding alone in preventing rebleeding. It should be part of the therapeutic armamentarium of every Canadian hospital.

hepatic and systemic hemodynamics in patients with portal hypertension, comparison with vasopressin. J Hepatol 1986;3:S53.

11. Eriksson LS, Wahren J. Intravenous and subcutaneous administration of a long-acting somatostatin analogue: effects on glucose metabolism and splanchnic haemodynamics in healthy subjects. Eur J Clin Invest 1989;19:213-9.

12. Hanisch E, Doertenbach J, Usadel KH. Somatostatin in acute bleeding oesophageal varices. Pharmacology and rationale for use. Drugs 1992;44(Suppl 2):24-35,70-2.

13. Sonnenberg GE, Keller U, Perruchoud A, Burckhardt D, Gyr K. Effect of somatostatin on splanchnic hemodynamics in patients with cirrhosis of the liver and in normal subjects. Gastroenterology 1981;80:526-32

14. Merkel C, Gatta A, Zuin R, Finucci GF, Nosadini R, Ruol A. Effect of somatostatin on splanchnic hemodynamics in patients with liver cirrhosis and portal hypertension. Digestion 1985;32:92-8.

15. Lin HC, Tsai YT, Lee FY, et al. Hemodynamic evaluation of octreotide in patients with hepatitis B-related cirrhosis. Gastroenterology 1992;103:229-34.

16. McCormick PA, Dick R, Siringo S, et al. Octreotide reduces azygous blood flow in cirrhotic patients with portal hypertension. Eur J Gastroenterol Hepatol 1990;2:489-92.

17. Rigau J, Bosch J, Bordas JM, et al. Endoscopic measurement of variceal pressure in cirrhosis: correlation with portal pressure and variceal hemorrhage. Gastroenterology 1989;96:873-80.

18. Kleber G, Sauerbruch T, Fischer G, Paumgartner G. Somatostatin does not reduce oesophageal variceal pressure in liver cirrhotics. Gut 1988;29:153-6.

19. Primignani M, Vazzoler MC, Carpinelli L, et al. The effect of octreotide on intraesophageal variceal pressure in liver cirrhosis is unpredictable. Hepatology 1990;12:989. (Abst 607)

20. Nevens F, Van Steenbergen W, Yap SH, Fevery J. Assessment of variceal pressure by continuous non-invasive endoscopic registration: 
a placebo controlled evaluation of the effect of terlipressin and octreotide. Gut 1996;38:129-34.

21. Burroughs AK, McCormick PA, Hughes MD, Sprengers D, D'Heygere F, McIntyre N. Randomized, double-blind, placebo-controlled trial of somatostatin for variceal bleeding. Emergency control and prevention of early variceal rebleeding. Gastroenterology 1990;99:1388-95.

22. Valenzuela JE, Schubert T, Fogel MR, et al. A multicenter, randomized, double-blind trial of somatostatin in the management of acute hemorrhage from esophageal varices. Hepatology 1989;10:958-61.

23. Imperiale TF, Teran JC, McCullough AJ. A meta-analysis of somatostatin versus vasopressin in the management of acute esophageal variceal hemorrhage. Gastroenterology 1995;109:1289-94.

24. Jaramillo JL, de la Mata M, Mino G, Costan G, Gomez-Camacho F. Somatostatin versus Sengstaken balloon tamponade for primary haemostasia of bleeding esophageal varices. A randomized pilot study. J Hepatol 1991;12:100-5.

25. Avgerinos A, Klonis C, Rekoumis G, Gouma P, Papadimitriou N, Raptis S. A prospective randomized trial comparing somatostatin, balloon tamponade and the combination of both methods in the management of acute variceal haemorrhage. J Hepatol 1991;13:78-83.

26. Planas R, Quer JC, Boix J, et al. A prospective randomized trial comparing somatostatin and sclerotherapy in the treatment of acute variceal bleeding. Hepatology 1994;20:370-5.

27. Sung JJ, Chung SC, Lai CW, et al. Octreotide infusion or emergency sclerotherapy for variceal haemorrhage. Lancet 1993;342:637-41.

28. Sung JJ, Chung SC, Yung MY, et al. Prospective randomised study of effect of octreotide on rebleeding from oesophageal varices after endoscopic ligation. Lancet 1995;346:1666-9.

29. Besson I, Ingrand P, Person B, et al. Sclerotherapy with or without octreotide for acute variceal bleeding. N Engl J Med 1995;333:555-60.
SMS 201-995 and oesophageal tamponade in the control of acute variceal haemorrhage. HPB Surg 1992;6:7-17.

31. Primignani M, Andreoni B, Carpinelli L, et al. Sclerotherapy plus octreotide versus sclerotherapy alone in the prevention of early rebleeding from esophageal varices: a randomized, double-blind, placebo-controlled, multicenter trial. New Italian Endoscopic Club. Hepatology 1995;21:1322-7.

32. Hwang SJ, Lin HC, Chang CF, et al. A randomized controlled trial comparing octreotide and vasopressin in the control of acute esophageal variceal bleeding. J Hepatol 1992;16:320-5.

33. Silvain C, Carpentier S, Sautereau D, et al. Terlipressin plus transdermal nitroglycerin vs octreotide in the control of acute bleeding from esophageal varices: a multicenter randomized trial. Hepatology 1993;18:61-5.

34. Pedretti G, Elia G, Calzetti C, et al. Octreotide versus terlypressin in acute variceal hemorrhage in liver cirrhosis. Clin Investig 1994;72:653-9.

35. Burroughs AK. Octreotide in variceal bleeding. Gut 1994;35:S23-7.

36. Laine L, Cook D. Endoscopic ligation compared with sclerotherapy for treatment of esophageal variceal bleeding. A meta-analysis. Ann Intern Med 1995;123:280-7.

37. Stiegmann GV, Goff JS, Michaletz-Onody PA, et al. Endoscopic sclerotherapy as compared with endoscopic ligation for bleeding esophageal varices. N Engl J Med 1992;326:1527-32.

38. Soderlund C, Magnusson I, Torngren S, Lundell L. Terlipressin (triglycyl-lysine vasopressin) controls acute bleeding oesophageal varices. A double-blind, randomized, placebo-controlled trial. Scand J Gastroenterol 1990;25:622-30.

39. Lin HJ, Perng CL, Wang K, Lee CH, Lee SD. Octreotide for arrest of peptic ulcer hemorrhage - A prospective, randomized controlled trial. Hepatogastroenterology 1995;42:856-60.

30. McKee RF, Garden OI, Anderson IR, Carter DC. A comparison of 


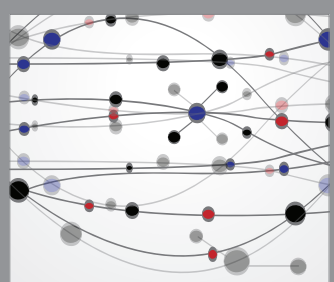

The Scientific World Journal
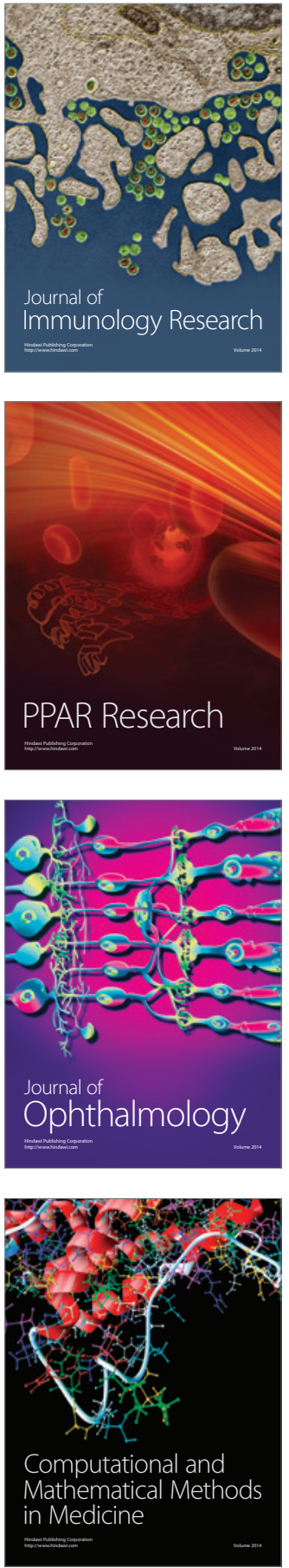

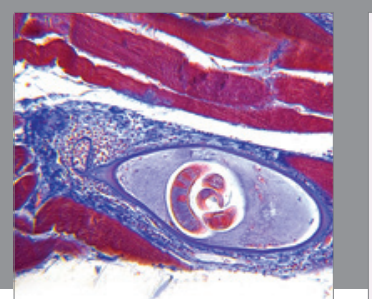

Gastroenterology Research and Practice

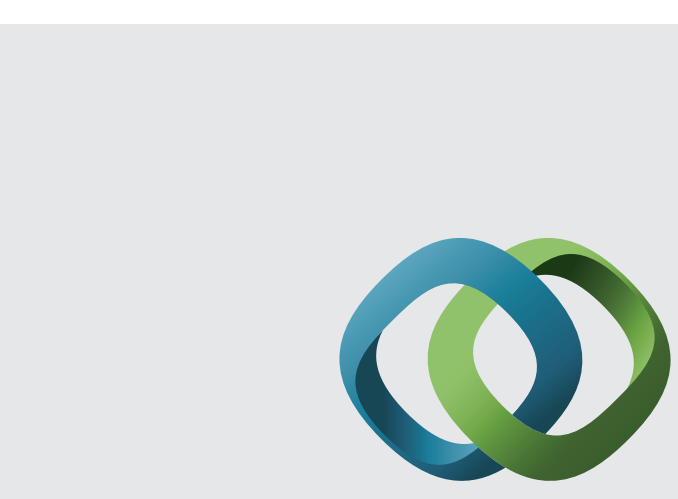

\section{Hindawi}

Submit your manuscripts at

http://www.hindawi.com
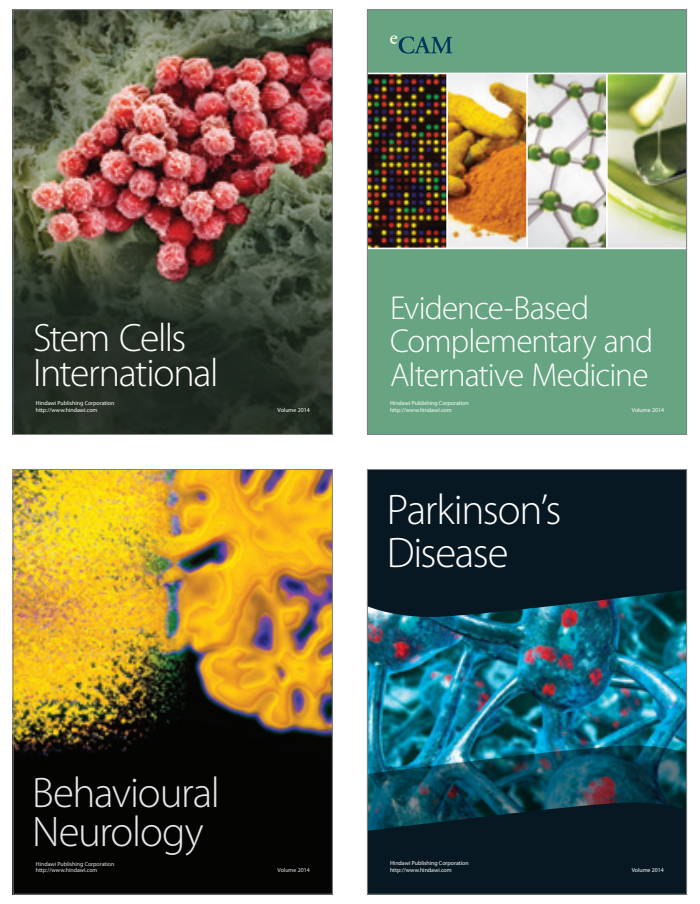
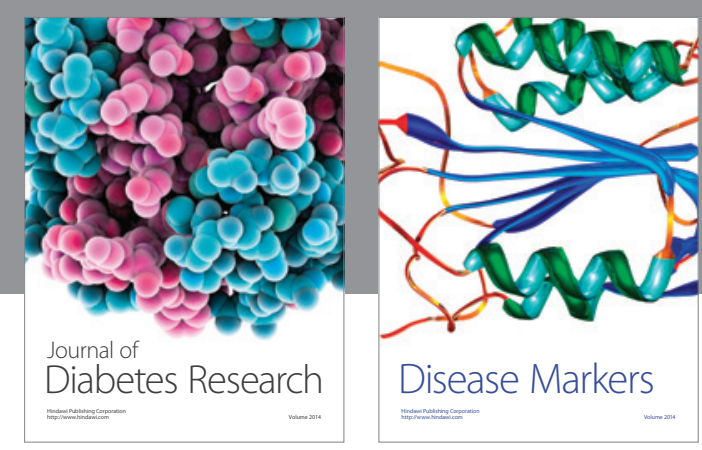

Disease Markers
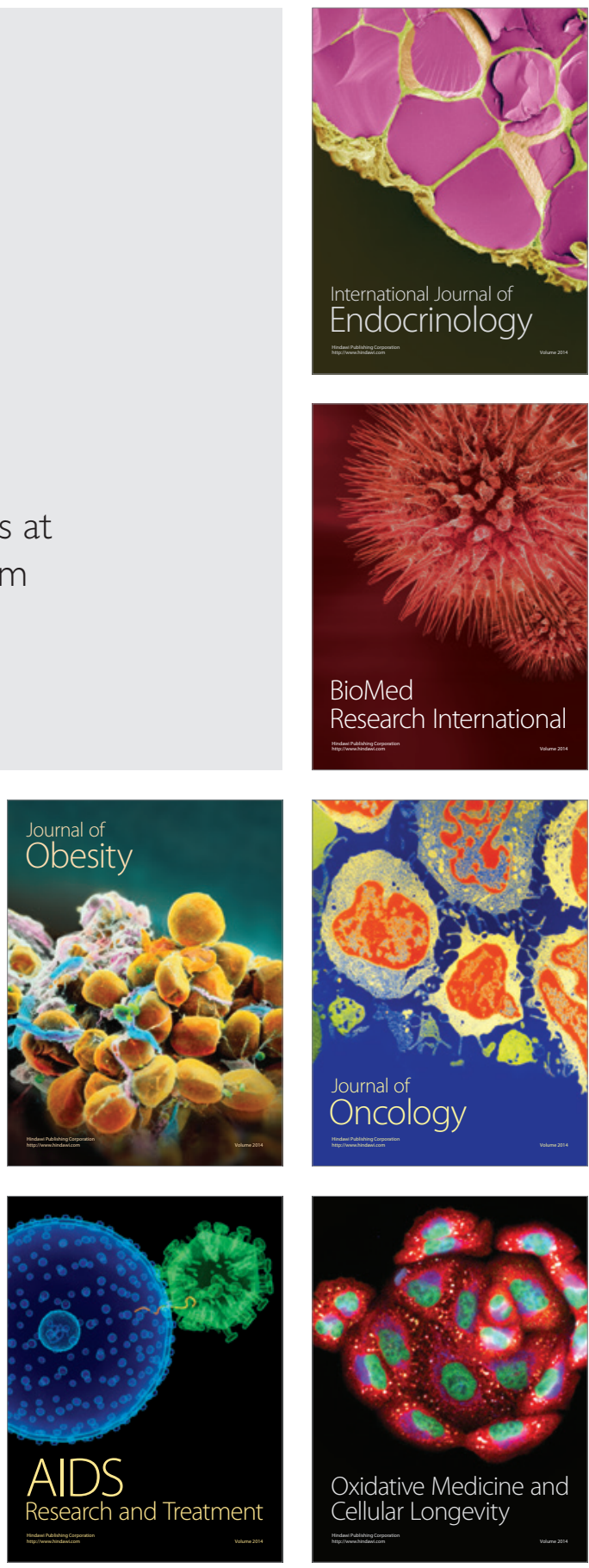